\title{
ANALISIS BATAKO DENGAN CAMPURAN SERBUK KACA SEBAGAI PENGGANTI PASIR
}

\author{
Rahmat $^{1}$, Irna Hendriyani ${ }^{2}$, Risma Sa'diyah ${ }^{3}$ \\ ${ }^{1,2}$ Prodi Teknik Sipil Universitas Balikpapan \\ ${ }^{3}$ Kader Teknik Desa Babulu Darat Penajam Paser Utara \\ rihtrusli@gmail.com
}

\begin{abstract}
ABSTRAK
Inovasi pemanfaatan limbah kaca dalam bidang konstruksi salah satunya sebagai bahan campuran batako. Dalam penelitian ini serbuk kaca dari bongkaran bangunan di daerah Klandasan Balikpapan, dimanfaatkan sebagai bahan pengganti pasir pada campuran batako. Penelitian ini bertujuan untuk menganalisis penggunaan serbuk kaca sebagai pengganti pasir pada campuran batako berdasarkan SNI 03-0349-1989. Benda uji batako dibuat dengan perbandingan semen dan pasir sebesar $1: 6$. Variasi dalam penggantian serbuk kaca yang digunakan sebesar 0\%, 25\%, dan 50\% dari komposisi pasir. Dari hasil analisis diperoleh bahwa daya serap air batako dengan penambahan serbuk kaca pada campuran batako sebagai pengganti pasir pada batako $0 \%$ serbuk kaca lebih besar 5,13\% dari variasi serbuk kaca 25\% dan lebih besar 17,1\% dari variasi 50\% serbuk kaca. Kuat tekan batako dengan penambahan serbuk kaca sebagai pengganti pasir pada campuran batako kuat tekan batako $25 \%$ serbuk kaca lebih baik $11,11 \%$ dari batako $0 \%$ serbuk kaca dan kuat tekan batako $50 \%$ serbuk kaca lebih baik 33,33\% dari batako 0\% serbuk kaca. Berdasarkan SNI 03-0349-1989, daya serap air dan kuat tekan pada batako dengan penambahan serbuk kaca sebagai pengganti pasir masih memenuhi persyaratan.
\end{abstract}

Kata kunci: batako, daya serap batako, kuat tekan batako, serbuk kaca

\section{ABSTRACT}

One of the innovations in the use of glass waste in the construction sector is as a mixture of concrete brick. In this research glass dust from a building demolition in the Klandasan area of Balikpapan was used as a substitute for sand in a mixture of concrete brick. This research aims to analyze the use of glass powder as a substitute for sand in a mixture of concrete brick based on SNI 03-0349-1989. Concrete brick specimens are made with a cement and sand ratio of 1: 6 . The variation in the replacement of glass powder used is $0 \%, 25 \%$, and $50 \%$ of the composition of the sand. From the results of the analysis it was found that the water absorption capacity of the concrete brick with the addition of glass powder to the mixture of the concrete brick as a substitute for sand in the $0 \%$ concrete brick glass powder was $5.13 \%$ greater than the variation of $25 \%$ glass powder and $17.1 \%$ greater than the $50 \%$ variation of glass powder. The compressive strength of the concrete brick making with the addition of glass powder as a substitute for sand in the mixture of the concrete brick compressive strength of $25 \%$ glass powder is $11.11 \%$ better than oncrete brick $0 \%$ glass powder and compressive strength of the concrete brick $50 \%$ glass powder is better $33.33 \%$ than concrete brick $0 \%$ glass powder. Based on SNI 03-0349-1989, water absorption and compressive strength on concrete brick with the addition of glass powder as a substitute for sand still meet the requirements.

Keywords : concrete brick, concrete brick water absorption, concrete brick compressive strength, glass powder 


\section{PENDAHULUAN}

Bahan bangunan yang tersusun dari komposisi antara pasir, semen dan air salah satunya adalah batako. Batako merupakan salah satu alternatif bahan dinding yang murah dan relatif kuat. Meskipun sifatnya hanya bagian non struktural dari bangunan bukan berarti batako tidak memiliki standar kekuatan dan toleransi yang harus dipenuhi. Karena dalam penggunaannya batako dengan mutu tertentu dapat dipakai dalam konstruksi yang memikul beban. Standar Nasional Indonesia (SNI 030349-1989) menyebutkan tentang persyaratan-persyaratan Bata Beton untuk Pasangan Dinding.

Banyaknya permintaan batako di pasaran membuat kebutuhan bahan baku utama konstruksi meningkat, salah satunya adalah pasir. Dengan meningkatnya kebutuhan pasir, akan membuat harga pasir pun semakin tinggi. Ini akan menjadi satu masalah bagi daerah-daerah yang minim menghasilkan pasir. Sehingga tidak heran jika harga pasir di daerah tersebut menjadi mahal. Karenanya diperlukan pengembangan suatu bahan yang dapat menggantikan atau mengurangi kebutuhan pasir tersebut untuk mengurangi biaya bahan baku tanpa mengurangi kualitas hasil. Beberapa inovasi yang sudah dilakukan seperti penambahan limbah kertas HVS pada campuran batako (Irna Hendriyani, 2017) dan serbuk kaca pada campuran batako (Nursyamsi, dkk, 2016).

Salah satu inovasi pemanfaatan kembali limbah kaca adalah sebagai bahan tambah dalam pembuatan batako. Limbah kaca merupakan limbah yang mudah didapatkan di lingkungan sekitar, baik dari sisa tempat minuman atau barang lain yang terbuat dari kaca. Kaca merupakan bahan yang sangat sulit terurai, penguraian kaca membutuhkan waktu jutaan tahun lamanya (William Liang, 2016). Karenanya pemanfaatan kembali penggunaannya akan berdampak pada pengurangan keberadaan limbah kaca di alam dan tentu berefek baik pada lingkungan.

Limbah kaca yang terdapat pada kota besar berdasarkan data Statistik Persampahan Indonesia tahun 2008 sebanyak 0,7 ton per tahun dan angka tersebut terus meningkat setiap tahunnya. Limbah kaca didaur ulang kembali menjadi serbuk kaca kemudian digunakan sebagai bahan tambah pada pembuatan batako. Indah Handayasari, (2016), Nursaymasi, dkk (2016) dan William Liang, dkk
(2017) melakukan penelitian tentang penambahan serbuk kaca sebagai pengganti semen pada campuran bata beton pejal, sementara Ali Syafi'urroziq, dkk (2018) dan Yuliana Andyani, dkk (2018) melakukan penelitian serbuk kaca sebagai bahan tambah dalam campuran batako Perbedaan penelitian ini dengan penelitian lainnya adalah bahwa serbuk kaca yang dihasilkan akan digunakan sebagai bahan campuran pasir. Batako yang diberikan bahan campuran serbuk kaca diharapkan dapat meningkatkan kekuatan pada batako tersebut atau setidaknya menyamai dengan kekuatan pada batako tanpa bahan tambah serbuk kaca (Rahman, 2016).

Rumusan masalah pada penelitian ini adalah:

1. Bagaimana jumlah kadar air batako dengan campuran serbuk kaca sebanyak 0\%, 25\%, dan $50 \%$ dari penggunaan pasir?

2. Bagaimana mutu batako dengan campuran serbuk kaca sebanyak 0\%, 25\%, dan 50\% dari penggunaan pasir? dan kuat tekannya.

Tujuan penelitian ini adalah:

1. Menganalisis jumlah kadar air batako dengan campuran serbuk kaca sebanyak 0\%, 25\%, dan $50 \%$ dari penggunaan pasir?

2. Menganalisis mutu batako dengan campuran serbuk kaca sebanyak 0\%, 25\%, dan 50\% dari penggunaan pasir?

Batasan masalah yang digunakan pada penelitian ini adalah:

1. Penelitian ini mengunakan limbah kaca dari bongkaran bangunan gedung di Balikpapan.

2. Komposisi limbah serbuk kaca digunakan sebagai substitusi pasir pada batako dengan variasi persentase serbuk kaca terhadap pasir yaitu $0 \%, 25 \%$ dan $50 \%$.

3. Parameter pengujian adalah uji kuat tekan batako pada umur umur 7, 14, 21 dan 28 hari untuk semua variasi.

4. Menggunakan cetakan batako ukuran $40 \mathrm{~cm} \times$ $10 \mathrm{~cm} \times 8 \mathrm{~cm}$.

5. Pasir yang digunakan adalah pasir Samboja.

\section{TINJAUAN PUSTAKA}

\section{Batako}

Batako merupakan bahan bangunan yang berupa bata cetak alternatif pengganti batu bata yang tersusun dari komposisi antara pasir, semen 
portland dan air dengan perbandingan 1 semen: 6 pasir. Persyaratan batako menurut SK SNI S-04-1989F dibedakan atas:

1. Bata beton pejal mutu I, yaitu bata beton padat yang digunakan untuk konstruksi yang tidak terlindung (konstruksi diluar atap).

2. Bata beton pejal mutu II, yaitu bata beton padat yang digunakan untuk konstruksi yang memikul beban, tetapi penggunaanya hanya untuk konstruksi yang terlindung dari cuaca luar (konstruksi dibawah atap).

3. Bata beton pejal mutu III, yaitu bata beton padat yang digunakan untuk konstruksi yang tidak memikul beban, untuk dinding penyekat serta konstruksi lainnya tetapi permukaan tidak diplester (dibawah atap).

4. Bata beton pejal mutu IV, yaitu bata beton padat yang digunakan untuk konstruksi seperti penggunaan dalam mutu III tetapi selalu terlindungi dari hujan dan terik matahari (diplester dan dibawah atap).

Persyaratan mutu batako serta syarat ukuran standar dan toleransi dimensinya (ukuran panjang, lebar dan tebal) seperti Tabel 1 dan Tabel 2.

Tabel 1. Persyaratan Fisik Batako Berdasarkan SNI

\begin{tabular}{lccccc}
\hline \multirow{2}{*}{ Syarat Fisis } & Satuan & \multicolumn{5}{c}{ Tingkat Mutu Bata Beton Pejal } \\
\cline { 3 - 6 } & & I & II & III & IV \\
\hline $\begin{array}{l}\text { Kuat tekan } \\
\text { bruto rata-rata } \\
\text { minimum }\end{array}$ & $\mathrm{Kg} / \mathrm{cm}^{2}$ & 100 & 70 & 40 & 25 \\
\hline $\begin{array}{l}\text { Kuat tekan } \\
\text { bruto masing- } \\
\text { masing benda } \\
\text { uji }\end{array}$ & $\mathrm{Kg} / \mathrm{cm}^{2}$ & 90 & 65 & 35 & 21 \\
\hline $\begin{array}{l}\text { Penyerapan air } \\
\text { rata-rata } \\
\text { maksimum }\end{array}$ & $\%$ & 25 & 35 & - & - \\
\hline
\end{tabular}

Sumber : SNI 03-0349-1989

Tabel 2. Syarat Ukuran Standar dan Toleransi Ukuran Batako

\begin{tabular}{|c|c|c|c|c|c|}
\hline \multirow[t]{2}{*}{ Jenis } & \multicolumn{3}{|c|}{ Ukuran } & \multicolumn{2}{|c|}{$\begin{array}{c}\text { Tebal dinding } \\
\text { sekatan lubang, } \\
\text { minimum }\end{array}$} \\
\hline & Panjang & Lebar & Tebal & Luar & Dalam \\
\hline 1. Pejal & $\begin{array}{r}390+3 \\
-5\end{array}$ & $90 \pm 2$ & $100 \pm 2$ & - & - \\
\hline \multicolumn{6}{|l|}{ 2. Berlubang } \\
\hline Kecil & $\begin{array}{c}390+3 \\
-5\end{array}$ & $\begin{array}{c}190+3 \\
-5\end{array}$ & $100 \pm 2$ & 20 & 15 \\
\hline Besar & $\begin{array}{c}390+3 \\
-5\end{array}$ & $\begin{array}{c}190+3 \\
-5\end{array}$ & $200 \pm 3$ & 25 & 20 \\
\hline
\end{tabular}

Sumber : SNI 03-0349-1989
Agar didapat mutu batako yang berkualitas, banyak faktor yang mempengaruhi. Faktor yang mempengaruhi kualitas batako tergantung pada faktor air semen, umur batako, kepadatan batako, bentuk tekstur batuan, ukuran agregat, kekuatan agregat, dan lain-lain (Rahman, 2016).

\section{Pasir}

Menurut William Liang (2016), pasir merupakan bahan butiran batuan halus yang berukuran $0,14-5 \mathrm{~mm}$, didapat dari hasil desintegrasi batuan alam (natural sand) atau dengan memecah (artificial sand). Pasir biasanya diperoleh dari penggalian di dasar sungai. Sebagai bahan adukan, baik untuk spesi maupun beton, maka pasir sebagai agregat halus harus diperiksa di lapangan. Hal-hal yang dapat dilakukan dalam pemeriksaan agregat halus di lapangan adalah:

1. Agregat halus terdiri dari butir-butir tajam dan keras. Butir agregat halus harus bersifat kekal, artinya tidak pecah atau hancur oleh pengaruhpengaruh cuaca.

2. Agregat halus tidak mengandung lumpur lebih dari 5\% (ditentukan terhadap berat kering). Apabila kadar lumpur melampaui 5\%, maka agregat halus harus dicuci.

3. Agregat halus tidak boleh mengandung bahanbahan organik terlalu banyak, hal tersebut dapat diamati dari warna agregat halus.

4. Agregat yang berasal dari laut tidak boleh digunakan sebagai agregat halus untuk semua adukan spesi dan beton (Rahman, 2016)

\section{Semen}

SNI 15-2049-2004 tentang Semen Portland mendefinisikan semen sebagai semen hidrolis yang dihasilkan dengan cara menggiling terak semen portland terutama yang terdiri atas kalsium silikat yang bersifat hidrolis dan digiling bersama-sama dengan bahan tambahan berupa satu atau lebih bentuk kristal senyawa kalsium sulfat dan boleh ditambah dengan bahan tambahan lain. Adapun ringkasan penggunaan dari jenis-jenis portland semen yaitu seperti tertera pada Tabel 3 .

Tabel 3. Jenis Semen dan Penggunaan

\begin{tabular}{clcc}
\hline Jenis & \multicolumn{3}{c}{ Penggunaan } \\
\hline I & $\begin{array}{l}\text { Konstruksi biasa dimana sifat yang khusus } \\
\text { tidak diperlukan }\end{array}$ & \\
\hline II & $\begin{array}{l}\text { Konstruksi biasa dimana diinginkan } \\
\text { perlawanan terhadap sulfat atau panas dari } \\
\text { hidrasi yang sedang }\end{array}$ & \\
\hline
\end{tabular}




\begin{tabular}{cl}
\hline III & $\begin{array}{l}\text { Jika kekuatan permulaan yang tinggi } \\
\text { diinginkan }\end{array}$ \\
\hline IV & Jika panas yang rendah dari hidrasi diinginkan \\
\hline V & $\begin{array}{l}\text { Jika daya tahan yang tinggi terhadap sulfat } \\
\text { diinginkan }\end{array}$ \\
\hline
\end{tabular}

Agar semen tetap memenuhi syarat meskipun disimpan dalam waktu lama, cara penyimpanan semen perlu diperhatikan (PB, 1989:13). Semen harus terbebas dari bahan kotoran dari luar. Semen dalam kantong harus disimpan dalam gudang tertutup, terhindar dari basah dan lembab, dan tidak tercampur dengan bahan lain. Semen dari jenis yang berbeda harus dikelompokkan sedemikian rupa untuk mencegah kemungkinan tertukarnya jenis semen yang satu dengan yang lainnya. Urutan penyimpanan harus diatur sehingga semen yang lebih dahulu masuk gudang terpakai lebih dahulu (Mulyono, 2005). Semen curah harus disimpan di dalam silo yang terbuat dari baja atau beton dan harus terhindar dari kemungkinan tercampur dengan bahan lainnya.

Apabila semen telah disimpan terlalu lama, perlu dibuktikan dulu bahwa semen tersebut memenuhi syarat sebelum dipakai. Untuk menghindari pecahnya kantong semen, tinggi maksimum penimbunan zak semen adalah 2 meter atau sekitar 10 zak. Jarak bebas antara bidang dinding dan semen sekitar $50 \mathrm{~cm}$, sedangkan jarak bebas antara lantai dan semen sekitar $30 \mathrm{~cm}$ (Mulyono, 2005).

\section{Air}

Air merupakan bahan penyusun batako air yang menyebabkan reaksi pengikatan dan berlangsungnya pengerasan, membasahi agregat dan sebagai pelumas campuran agar mudah dalam pengerjaannya. Air digunakan untuk membuat adukan menjadi bubur kental dan juga sebagai bahan untuk menimbulkan reaksi pada bahan lain untuk dapat mengeras. Oleh karena itu, air sangat dibutuhkan dalam pelaksanaan pengerjaan bahan. Tanpa air, konstruksi bahan tidak akan terlaksana dengan baik dan sempurna.

\section{Serbuk Kaca}

Kaca adalah salah satu produk industri kimia yang merupakan gabungan dari berbagai oksida anorganik yang tidak mudah menguap, yang dihasilkan dari dekomposisi dan peleburan senyawa alkali dan alkali tanah, pasir serta berbagai penyusun lainnya (Dian Wibowo, 2013).
Kaca memiliki sifat-sifat yang khas dibanding dengan golongan keramik lainnya. Kekhasan sifat-sifat kaca ini terutama dipengaruhi oleh keunikan silika $\left(\mathrm{SiO}_{2}\right)$ dan proses pembentukannya. Dian Wibowo (2013) menjelaskan reaksi yang terjadi dalam pembuatan kaca secara ringkas pada persamaan berikut.

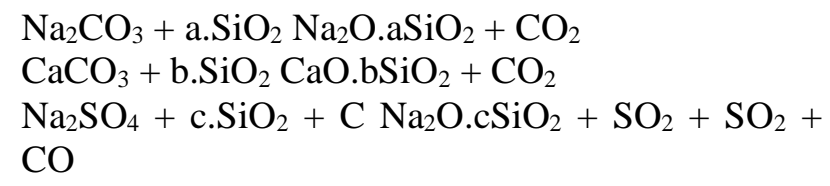

Penggunaan agregat halus kaca yang dibuat dari jenis kaca leburan, mulai dikembangkan untuk membuat beton kinerja tinggi. Agregat halus kaca ini dibuat dalam bentuk bubuk dengan ukuran dan distribusi yang serupa agregat halus/pasir alam. Penggunaannya diharapkan dapat memanfaatkan limbah dari hasil samping industri untuk komponen industri konstruksi dan untuk mengatasi kekurangan pasir alam yang tersedia. Berdasarkan ASTM C289-87 dilakukan tes kimia dan tes kereaktifan agregat didapat bahwa bubuk kaca masih layak digunakan sebagai agregat walaupun memiliki sifat "merugikan" karena mengandung silika reaktif yang dapat bereaksi dengan alkali semen, sehingga mengakibatkan terjadinya ekspansi beton (Wibowo, 2013).

\section{Daya Serap Air}

Besar kecilnya penyerapan air oleh batako sangat dipengaruhi oleh pori-pori atau rongga yang terdapat pada batako tersebut. Semakin banyak pori-pori yang terkandung dalam batako maka akan semakin besar pula penyerapan air sehingga ketahanannya akan berkurang. Rongga (pori-pori) yang terdapat pada batako terjadi karena kurang tepatnya kualitas dan komposisi material penyusunnya. Pengaruh rasio yang terlalu besar dapat menyebabkan rongga karena terdapat air yang tidak bereaksi dan kemudian menguap dan meninggalkan rongga (Sipayung.M. 1995). Persentase penyerapan air menggunakan persamaan (SNI 03- 0349-1989)

$$
\% \text { air }=\frac{\text { berat basah }- \text { berat kering }}{\text { berat kering }} \times 100 \%
$$




\section{Kuat Tekan}

Kuat tekan (Compressive strength) adalah suatu bahan yang merupakan perbandingan besamya beban maksimum yang dapat ditahan dengan luas penampang bahan yang mengalami gaya tersebut (Mariq R, 2009). Kuat tekan batako mengidentifikasi mutu dari sebuah struktur. Semakin tinggi tingkat kekuatan struktur yang dikehendaki, semakin tinggi pula mutu batako yang dihasilkan (Ali Syafi'urroziq, 2018). Batako harus dirancang proporsi campurannya agar menghasilkan suatu kuat tekan rerata yang disyaratkan. Pada tahap pelaksanaan konstruksi, batako yang telah dirancang campurannya harus diproduksi sedemikian rupa sehingga memperkecil frekuensi terjadinya batako dengan kuat tekan yang lebih rendah dari seperti yang telah disyaratkan. Untuk menghitung besamya kuat tekan dipergunakan persamaan:

$$
\text { Kuat Tekan }=\frac{P}{A}
$$

Dimana: $\mathrm{P}=$ beban maksimum $(\mathrm{Kn})$

$$
\mathrm{A}=\underset{\left(\mathrm{cm}^{2}\right)}{\text { Luas penampang bidang tekan }}
$$

\section{METODE PENELITIAN}

Metode yang digunakan dalam penelitian ini adalah metode penelitian eksperimen. Faktor yang diteliti adalah komposisi campuran serbuk kaca pada batako, dengan tujuan untuk mengetahui pengaruh serbuk kaca sebagai bahan pengganti pasir sebagai agregat halus pada ukuran, daya serap air, dan kuat tekan. Rancangan penelitian pada batako akan dibuat benda uji dengan perbandingan campuran 1Pc : 6Ps (William Liang, 2017), dimana campuran ini akan diberi serbuk kaca sebagai bahan substitusi dengan mengurangi jumlah persentase dari berat pasir. Variasi perbandingan komposisi yang digunakan berdasarkan atas kategori perbandingan volume dari pasir, yaitu $0 \%, 25 \%$, dan $50 \%$ serbuk kaca dari berat pasir. Serbuk kaca yang digunakan adalah serbuk kaca lolos ayakan no. 200. Pembuatan benda uji dan prosedur pengujian kualitas sesuai dengan yang telah ditentukan dalam Standar Nasional Indonesia (SNI 03-0349-1989).
Bahan-bahan yang digunakan adalah:

$>$ Semen Portland, tipe 1 dengan merk dagang Tiga Roda dalam kemasan $50 \mathrm{~kg}$.

> Pasir, Pasir yang umumnya digunakan dalam pembuatan batako di Balikpapan adalah pasir Samboja.

> Air dari PDAM Balikpapan

$>$ Serbuk Kaca yang berasal dari bongkaran bangunan di daerah Klandasan Balikpapan. Kaca ini merupakan kaca dari kaca jendela bangunan tersebut yang ditemukan dalam keadaan pecah-pecah. Proses penghalusan kaca selanjutnya dilakukan di Laboratorium Teknik Sipil Universitas Balikpapan.

Tahapan-tahapan pelaksanaan adalah sebagai berikut:

1. Cara pembuatan batako, disiapkan dan ditimbang sesuai dengan variasi yang direncanakan untuk setiap adukan. Kemudian bahan-bahan tersebut dimasukkan satu persatu ke dalam molen dan diputar hingga adukan tercampur rata. Setelah itu adukan tersebut dituangkan ke dalam cetakan batako. Proses pemadatan dilakukan dengan cara ditekan atau dipukul dengan tongkat besi agar didapatkan hasil yang padat dan rapat. Setelah itu benda uji dikeluarkan dari cetakan dan diletakkan di tempat yang permukaannya rata.

2. Cara perawatan benda uji batako yang telah dicetak adalah dengan cara disimpan di tempat yang terlindung dari sinar matahari dan curah hujan secara langsung. Benda uji diletakkan di tempat yang tidak menyerap air dan bagian atas benda uji ditutupi dengan plastik.

3. Untuk pengujian daya serap batako, benda uji direndam dalam air bersih bersuhu ruangan selama 24 jam. Kemudian benda uji diangkat dari rendaman, dan air sisanya dibiarkan meniris \pm satu menit. Lalu permukaan bidang benda uji diseka dengan kain lembab, untuk mengurangi air yang berlebihan pada benda uji. Setelah itu benda uji ditimbang. Kemudian benda uji dikeringkan dengan suhu $105 \pm 5^{\circ} \mathrm{C}$, sampai beratnya pada dua kali penimbangan tidak berbeda.

4. Pengujian daya serap batako dilakukan pada umur 3 hari dengan jumlah benda uji sebanyak lima buah untuk tiap variasi.

5. Untuk pengujian kuat tekan batako, benda uji diletakkan pada mesin tekan yang dapat diatur kecepatan penekanannya. Kecepatan penekanan 
6. dari mulai pemberian beban sampai benda uji hancur. Kuat tekan benda uji dihitung dengan dengan membagi beban maksimum pada waktu benda uji hancur, dengan luas bidang tekan bruto.

7. Pengujian kuat tekan batako dilakukan pada umur 7, 14, dan 28 hari.

8. Jumlah benda uji untuk setiap variasi sebanyak 5 sampel uji.

9. Total benda uji yang dibuat dalam penelitian ini berjumlah 80 benda uji, dengan perincian 20 benda uji untuk pengujian daya serap dan 60 benda uji untuk pengujian kuat tekan.

\section{HASIL DAN PEMBAHASAN}

\section{Komposi Campuran Batako}

Komposisi campuran 1 batako untuk tiap variasi seperti terlihat pada Tabel 4.

Tabel 4. Komposisi Campuran 1 Batako Tiap Variasi

\begin{tabular}{cccc}
\hline $\begin{array}{c}\text { Variasi } \\
(\%)\end{array}$ & $\begin{array}{c}\text { Semen } \\
(\mathrm{kg})\end{array}$ & $\begin{array}{c}\text { Pasir } \\
(\mathrm{kg})\end{array}$ & $\begin{array}{c}\text { Serbuk Kaca } \\
(\mathrm{kg})\end{array}$ \\
\hline 0 & 2,3 & 13,7 & 0,0 \\
\hline 25 & 2,3 & 10,3 & 3,4 \\
\hline 50 & 2,3 & 6,9 & 6,9 \\
\hline
\end{tabular}

Sumber: hasil analisis

\section{Pengujian Daya Serap Batako}

Pada pengujian daya serap batako mengunakan 3 buah sampel yaitu, 1 buah sampel dari masing-masing variasi. Hasil pengujian daya serap batako terlihat pada Tabel 5 .

Tabel 5 Pengujian Daya Serap Air Batako

\begin{tabular}{cccc}
\hline $\begin{array}{c}\text { Variasi } \\
\begin{array}{c}\text { Serbuk } \\
\text { Kaca }\end{array}\end{array}$ & $\begin{array}{c}\text { Berat } \\
\text { basah }\end{array}$ & $\begin{array}{c}\text { Berat } \\
\text { kering }\end{array}$ & $\begin{array}{c}\text { Penyerapan } \\
(\%)\end{array}$ \\
\hline $0 \%$ & 17.535 & 16.840 & 4,1 \\
\hline $25 \%$ & 18.065 & 17.385 & 3,9 \\
\hline $50 \%$ & 18.252 & 17.636 & 3,5 \\
\hline
\end{tabular}

Sumber: Hasil analisis

Bila dibuat dalam bentuk grafik seperti terlihat pada Gambar 1.

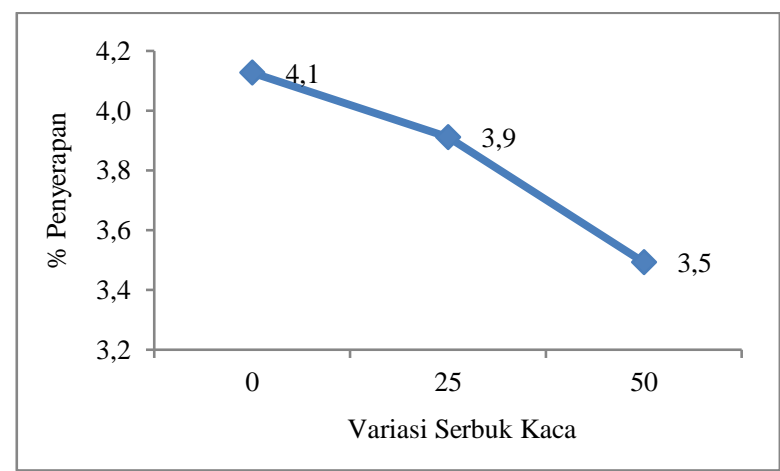

Gambar 1 Grafik daya serap air batako ringan

Berdasarkan Tabel 5 dan Gambar 1, didapatkan bahwa daya serap air berbanding terbalik dengan bertambahnya serbuk kaca. Untuk variasi $0 \%$ kaca sebesar $4,1 \%$. Variasi serbuk kaca $25 \%$ menurun $5,13 \%$ dari varias $0 \%$, yaitu sebesar $3,9 \%$, dan variasi serbuk kaca $50 \%$ turun $17,1 \%$ dari variasi $0 \%$ sebesar $3,5 \%$. Hasil ini sesuai dengan persyaratan SNI 03-0349-1989, yaitu dibawah $25 \%$.

\section{Pengujian Kuat Tekan}

Pengujian kuat tekan dilakukan setelah benda uji berumur 7, 14, dan 28 hari. Dengan variasi campuran serbuk kaca 0\%, 25\%, dan 50\%. Adapun hasil uji kuat tekan batako terdapat pada Tabel 6, Tabel 7, dan Tabel 8.

Tabel 6 Hasil Pengujian Kuat Tekan Batako Variasi $0 \%$ serbuk Kaca

\begin{tabular}{cccc}
\hline \multirow{2}{*}{$\begin{array}{c}\text { Ke- } \\
\text { Keri }\end{array}$} & $\begin{array}{c}\text { Pembacaan Dial } \\
\text { Rata-rata }\end{array}$ & $\begin{array}{c}\text { Luas } \\
\text { Permukaan }\end{array}$ & $\begin{array}{c}\text { Kuat } \\
\text { Tekan }\end{array}$ \\
\cline { 2 - 4 }$(\mathrm{kN})$ & 15 & 400 & 37,50 \\
\hline 14 & 16 & 400 & 40,00 \\
\hline 28 & 18 & 400 & 45,00 \\
\hline
\end{tabular}

Sumber:Hasil analisis

Tabel 7 Hasil Pengujian Kuat Tekan Batako

\begin{tabular}{cccc}
\multicolumn{4}{c}{ Variasi serbuk kaca $25 \%$} \\
Hari \\
Ke- & $\begin{array}{c}\text { Pembacaan Dial } \\
\text { Rata-rata }\end{array}$ & $\begin{array}{c}\text { Luas } \\
\text { Permukaan }\end{array}$ & Kuat Tekan \\
\cline { 2 - 4 } & $(\mathrm{kN})$ & $\left(\mathrm{cm}^{2}\right)$ & $\left(\mathrm{kg} / \mathrm{cm}^{2}\right)$ \\
\hline 7 & 16 & 400 & 40,00 \\
\hline 14 & 17 & 400 & 42,50 \\
\hline 28 & 20 & 400 & 50,00
\end{tabular}

Sumber: Hasil analisis 
Tabel 8. Hasil Pengujian Kuat Tekan Batako Variasi serbuk kaca 50\%

\begin{tabular}{cccc}
\hline \multirow{2}{*}{$\begin{array}{c}\text { Hari } \\
\text { Ke- }\end{array}$} & $\begin{array}{c}\text { Pembacaan Dial } \\
\text { Rata-rata }\end{array}$ & $\begin{array}{c}\text { Luas } \\
\text { Permukaan }\end{array}$ & Kuat Tekan \\
\cline { 2 - 4 } & $(\mathrm{kN})$ & $\left(\mathrm{cm}^{2}\right)$ & $\left(\mathrm{kg} / \mathrm{cm}^{2}\right)$ \\
\hline 7 & 18 & 400 & 45,00 \\
\hline 14 & 20 & 400 & 50,00 \\
\hline 28 & 24 & 400 & 60,00 \\
\hline
\end{tabular}

Sumber: Hasil analisis

Dari Tabel 6, Tabel 7, dan Tabel 8 apabila disajikan dalam bentuk grafik seperti terlihat pada Gambar 2.

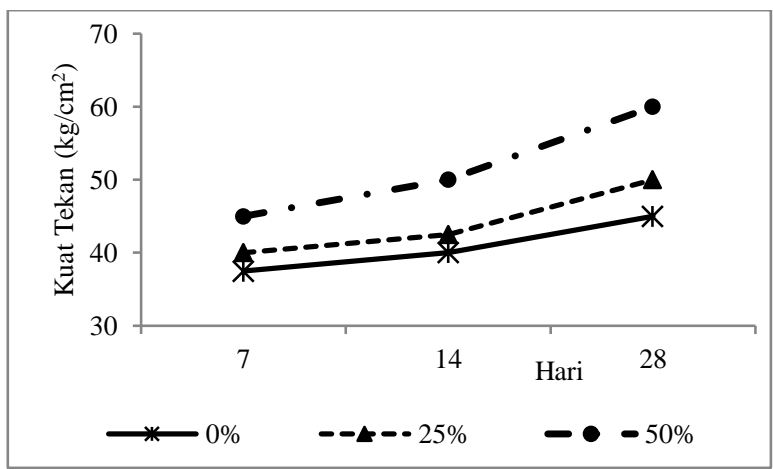

Gambar 2 Kuat Tekan Batako pada umur 7, 14, dan 28 hari dari berbagai variasi

Sumber: Hasil analisis

Berdasarkan Tabel 6, Tabel 7, Tabel 8, dan Gambar 2 tentang analisa kuat tekan batako didapatkan bahwa kuat tekan rata-rata pada batako variasi $0 \%$ serbuk kaca adalah $37 \mathrm{~kg} / \mathrm{cm}^{2}$ pada umur 7 hari, $40 \mathrm{~kg} / \mathrm{cm}^{2}$ pada umur 14 hari, dan $45 \mathrm{~kg} / \mathrm{cm}^{2}$ pada umur 28 hari. Untuk variasi serbuk kaca 25\% serbuk kaca, diperoleh nilai kuat tekan rata-rata sebesar $40 \mathrm{~kg} / \mathrm{cm}^{2}$ pada umur 7 hari, $42 \mathrm{~kg} / \mathrm{cm}^{2}$ pada umur 14 hari dan $50 \mathrm{~kg} / \mathrm{cm}^{2}$ pada umur 28 hari. Sedangkan kuat tekan rata-rata pada batako variasi serbuk kaca $50 \%$ adalah $45 \mathrm{~kg} / \mathrm{cm}^{2}$ pada umur 7 hari, $50 \mathrm{~kg} / \mathrm{cm}^{2}$ pada umur 14 hari, dan 60 $\mathrm{kg} / \mathrm{cm}^{2}$ pada umur 28 hari. Menurut SNI 03-03491989, batako ini termasuk dalam mutu kelas III.

Bertambahnya variasi serbuk kaca ternyata membuat kuat tekan batako pun bertambah. Kuat tekan rata-rata tetinggi dicapai oleh batako dengan variasi 50\%. Kenaikan ini terjadi karena bertambahnya serbuk kaca yangn ditambahkan dalam campuran batako. Menurut Yuliana Andryani (2018), bahan penyusun serbuk kaca didominasi oleh silica $\left(\mathrm{SiO}_{2}\right)$. Silica sebagai bahan penyusun terbesar pada semen memiliki sifat mekanik yang sangat kuat. Sehingga penambahan kadar serbuk kaca sebagai pengganti pasir, membuat kuat tekan batakonya pun meningkat.

\section{PENUTUP}

\section{Kesimpulan}

Kesimpulan yang dapat diambil adalah sebagai berikut:

1. Daya serap air batako dengan penambahan serbuk kaca pada campuran batako sebagai pengganti pasir berbanding terbalik dengan bertambahnya serbuk kaca. Dimana daya serap air pada batako $0 \%$ serbuk kaca lebih besar $5,13 \%$ dari variasi serbuk kaca $25 \%$ dan lebih besar $17,1 \%$ dari variasi $50 \%$ serbuk kaca.

2. Kuat tekan batako dengan penambahan serbuk kaca sebagai pengganti pasir pada campuran batako berbanding lurus dengan penambahan variasi serbuk kaca. Dimana kuat tekan batako $25 \%$ serbuk kaca lebih baik $11,11 \%$ dari batako $0 \%$ serbuk kaca dan kuat tekan batako $50 \%$ serbuk kaca lebih baik 33,33\% dari batako 0\% serbuk kaca.

3. Berdasarkan SNI 03-0349-1989, daya serap air pada batako dengan penambahan serbuk kaca sebagai pengganti pasir masih memenuhi persyaratan dan berdasarkan mutunya, batako ini termasuk dalam kelas III.

\section{Saran}

1. Perlu dilakukan penelitian lebih lanjutan berkenaan dengan durability dan kemampuan menahan beban struktur, serta pengembangan penelitian terhadap bobot.

2. Perlu juga dilakukan pemeriksaan secara kimia terhadap serbuk kaca untuk mengetahui zat kimia yang dikandung serbuk kaca secara detail.

\section{DAFTAR PUSTAKA}

Andriyani, Yuliana., \& Nursyamsi. (2018). Pemanfaatan Serbuk Kaca Sebagai Bahan Tambah Dalam Pembuatan Batako, Skripsi Fakultas Teknik Universitas Sumatera Utara, Medan.

Badan Standardisasi Nasional. (1989). SNI 030349-1989 tentang Bata Beton untuk Pasangan Dinding. 
Analisis Batako Dengan Campuran..., Rahmat ${ }^{(1)}$, Irna Hendriyani( ${ }^{(2)}$ Risma Sa'diyah $^{(3)}$

Hendriyani, Irna., Rahmat., \& Devi, Suheriah Mulia. (2017). Kajian Pembuatan Batako Dengan Penambahan Limbah Kertas HVS, Prosiding SNITT Politeknik Negeri Balikpapan Tahun 2017. ISBN. 978-60251450-0-1. Balikpapan.

Nursyamsi., Indrawan, Ivan., \& Hastuty, Ika Puji. (2016). Pemanfaatan Serbuk Kaca Sebagai Bahan Tambah Dalam Pembuatan Batako, Media Teknik Sipil, Februari 2016, Volume 14, Nomor 1, ISSN 1693-3095, URL: http://ejournal.umm.ac.id/index.php/jmts/ article/view/3292, diakses pada 24 Oktober 2019.

Rahman, Muhammad Fathur. (2016). Pengaruh Penambahan Serbuk Kaca Pada Batako Sebagai Bahan Pembuat Dinding, Skripsi Fakultas Teknik Universitas Sumatera Utara, Medan

Syafi'urroziq, Ali., SP, Yosef Cahyo., \& Krisnawati, Lucia Desti. (2018). Pemanfaatan Serbuk Kaca Dari Jenis Kaca Bening Dengan Ketebalan 3-4 mm Sebagai Bahan Tambah Dalam Pembuatan Batako. Jurnal Manajemen Teknologi dan Teknik Sipil Universitas Kediri. Kediri

William, Liang., \& Nursyamsi. (2017). Analisa Kuat Tekan Batako Dengan Campura Serbuk Kaca Dan Silica Fume, Jurnal Teknik Sipil USU, Universitas Sumatera Utara, Medan 